\title{
Glucagon Administration by Nasal and Intramuscular Routes in Adults With Type 1 Diabetes During Insulin- Induced Hypoglycaemia: A Randomised, Open-Label, Crossover Study
}

\author{
Jeffrey G. Suico (1) - Ulrike Hövelmann · Shuyu Zhang • \\ Tong Shen • Brandon Bergman • Jennifer Sherr • Eric Zijlstra • \\ Brian M. Frier · Leona Plum-Mörschel
}

Received: April 15, 2020 / Published online: June 8, 2020

(C) The Author(s) 2020

\section{ABSTRACT}

Introduction: Many commercially available glucagon products for treatment of severe hypoglycaemia require cumbersome reconstitution and potentially intimidating injection during an emergency. Nasal glucagon (NG) is a novel drug-device combination product consisting of a single-use dosing device that delivers glucagon dry powder through nasal

Digital Features To view enhanced digital features for this article go to https://doi.org/10.6084/m9.figshare. 12319730.

Electronic Supplementary Material The online version of this article (https://doi.org/10.1007/s13300020-00845-7) contains supplementary material, which is available to authorized users.

J. G. Suico $(\bowtie) \cdot$ S. Zhang · T. Shen · B. Bergman Eli Lilly and Company, Indianapolis, IN, USA e-mail: suico_jeffrey_gideon@lilly.com

U. Hövelmann · E. Zijlstra

Profil, Neuss, Germany

J. Sherr

Endocrinology, Department of Pediatrics

(Endocrinology), Yale School of Medicine, New

Haven, CT, USA

B. M. Frier

The Queen's Medical Research Institute, University of Edinburgh, Edinburgh, UK

L. Plum-Mörschel

Profil, Mainz, Germany administration. The present study assessed whether $3 \mathrm{mg}$ NG was non-inferior to $1 \mathrm{mg}$ intramuscular glucagon (IMG) in adults with type 1 diabetes.

Methods: This randomised, open-label, twoperiod, crossover trial was conducted at two clinical sites. Hypoglycaemia (plasma glucose [PG] target of $<3.3 \mathrm{mmol} / \mathrm{l}(60 \mathrm{mg} / \mathrm{dl})$ was induced by an intravenous insulin infusion. Glucagon preparations were given by study staff. Treatment success was defined as an increase in PG to $\geq 3.9 \mathrm{mmol} / \mathrm{l}(70 \mathrm{mg} / \mathrm{dl})$ or an increase of $\geq 1.1 \mathrm{mmol} / \mathrm{l}(20 \mathrm{mg} / \mathrm{dl})$ from the PG nadir within $30 \mathrm{~min}$ of receiving glucagon.

Results: Of the 66 participants included in the primary efficacy analysis who received both NG and IMG, 100\% achieved treatment success, thus demonstrating non-inferiority of NG to IMG. All participants achieved treatment success within $25 \mathrm{~min}$ with the mean time to treatment success of $11.4 \mathrm{~min}(\mathrm{NG})$ and $9.9 \mathrm{~min}$ (IMG). No serious adverse events occurred. Forty-eight treatment-emergent adverse events (TEAEs) occurred after NG and 51 after IMG. Most TEAEs were mild and transient.

Conclusion: Nasal glucagon was as efficacious and well tolerated as IMG for the treatment of insulin-induced hypoglycaemia in adults and will be as useful as IMG as a rescue treatment for severe hypoglycaemia.

Trial Registration: NCT03339453, ClinicalTrials. gov 
Keywords: Insulin-induced hypoglycaemia; Intramuscular glucagon; Nasal glucagon; Type 1 diabetes

\section{Key Summary Points}

Why carry out this study?

Some available commercial glucagon products for treatment of severe hypoglycaemia require cumbersome reconstitution and potentially intimidating injection during an emergency

Nasal glucagon is a novel drug-device combination product consisting of a single-use dosing device that delivers glucagon dry powder through nasal administration

This study assessed whether administration of $3 \mathrm{mg}$ nasal glucagon was approximately equivalent in increasing glucose levels compared to $1 \mathrm{mg}$ of intramuscular glucagon in adults with type 1 diabetes

\section{What was learned from the study?}

Nasal glucagon successfully treats insulininduced hypoglycaemia in adults, comparable to intramuscular glucagon

Nasal glucagon was as well tolerated in adults and will be as useful as IMG as a rescue treatment for severe hypoglycaemia

\section{INTRODUCTION}

Individuals with insulin-treated diabetes are at risk of severe hypoglycaemia, which is defined as an event characterised by altered mental and/ or physical functioning that for recovery requires the assistance of another person to actively administer carbohydrate, administer glucagon, or perform other resuscitative actions [1].

Many commercially available glucagon emergency kits must be reconstituted using a multiple-step process before the drug can be administered to the patient by either subcutaneous or intramuscular injection. When administration of injectable glucagon was simulated under emergency conditions, $10 \%$ of parents of adolescents and children with type 1 diabetes failed to administer the drug and 70\% of parents reported having trouble using the kit [2]. Furthermore, the average time to administration of glucagon was $2.5 \mathrm{~min}$. More recently, a simulation study showed that when assessing either trained caregivers or volunteers (acquaintances) who had not been trained on how to use the product, only $13 \%$ of the caregivers and none of the volunteers were able to administer a full dose of the drug correctly [3]. Similarly, the time taken to administer glucagon was approximately $2 \mathrm{~min}$. Thus, even in simulated situations, delays or errors in glucagon administration can occur, including complete failure to administer the glucagon successfully, which illustrates the difficulty of using this rescue medication clinically to treat severe hypoglycaemia in an actual emergency setting [4]. Challenges in administrating and lack of familiarity and adequate training likely contribute to the underutilisation of injectable glucagon $[5,6]$.

Nasal glucagon (NG) is administered via a drug-device combination of a dry nasal powder spray with $3 \mathrm{mg}$ glucagon that delivers glucagon for absorption through the nasal mucosa [7]. Glucagon is not stable in solution, and NG overcomes this issue with a stable powder formulation. Thus, NG obviates the need for reconstitution and injection. The NG commercial drug product consists of synthetic glucagon with an amino acid sequence identical to human glucagon and uses the excipients dodecylphosphocholine, as a surfactant and absorption enhancer, and beta-cyclodextrin, as a filler/ bulking agent and absorption enhancer. Importantly, as NG is absorbed passively through the nasal mucosa, there is no need for patient inhalation. Because of these advantages, NG may offer a significant improvement in the 
treatment of severe hypoglycaemia outside the hospital setting.

Rickels et al. conducted a study using the clinical trial NG drug product [8]. To evaluate the commercial NG drug product, in the present study, using a design similar to that of Rickels et al., we assessed non-inferiority of NG to GlucaGen ${ }^{\circledR}$ (glucagon for intramuscular injection [IMG]) [6] in a cohort of adult participants with type 1 diabetes following controlled insulin-induced hypoglycaemia. This report also includes characterisation of the pharmacokinetics (PK) and pharmacodynamics (PD) of NG and IMG.

\section{METHODS}

\section{Ethics}

The study was conducted in accordance with the ethical principles of the Declaration of Helsinki and International Conference on Harmonisation's Guideline for Good Clinical Practice. The protocol was approved by the ethics committee of Ärztekammer Nordrhein Düsseldorf, Germany, and by the Ethik-Kommission der Landesärztekammer Mainz, Germany. All participants provided written informed consent.

\section{Study Design and Treatment}

This randomised, open-label, two-period, crossover trial was conducted at two clinical sites in Germany and used a commercial NG drug product. Participants were randomly assigned to receive either NG or IMG in the first period, followed by the alternate treatment in the second period (Supplemental Fig. 1). The first participant was enrolled in the study on 14 November 2017, and the last patient visit (follow-up) occurred on 13 January 2018. The results presented here represent data collected through the safety follow-up visit. This study was registered at https://www.clinicaltrials.gov (NCT03339453).

The primary objective of this study was to compare NG versus IMG in the percentage of adult participants with type 1 diabetes who achieved treatment success (an increase in PG to $\geq 3.9 \mathrm{mmol} / \mathrm{l}[70 \mathrm{mg} / \mathrm{dl}]$ or an increase of $\geq 1.1 \mathrm{mmol} / \mathrm{l}[20 \mathrm{mg} / \mathrm{dl}]$ from the PG nadir within $30 \mathrm{~min}$ of receiving glucagon) in response to controlled insulin-induced hypoglycaemia. The secondary objectives were to assess the safety and tolerability of NG versus IMG and to characterise the PD and PK profiles of NG versus IMG. Exploratory objectives included assessment of the occurrence and severity of hypoglycaemia symptoms during controlled insulin-induced hypoglycaemia.

\section{Participants and Eligibility Criteria}

Patients with type 1 diabetes were eligible if they were aged 18-64 years, had a diagnosis of type 1 diabetes for at least 2 years, received insulin as either multiple daily injections or continuous subcutaneous insulin infusion, and had a haemoglobin A1c (HbA1c) value $\leq 10 \%$ ( $\leq 86 \mathrm{mmol} / \mathrm{mol})$. Patients were excluded if they used systemic beta-adrenoceptor blockers, indomethacin, warfarin, or anti-cholinergic drugs daily; had experienced severe hypoglycaemia in the 1-month period prior to enrolling in the study; or had a history of insulinoma, epilepsy, or seizure disorder.

\section{Investigational Product, Comparator, Dose, and Administration}

Nasal glucagon was supplied as a lyophilised powder contained within a commercial drug product nasal delivery device assembly manufactured at a commercial scale. GlucaGen was supplied as part of the GlucaGen HypoKit (Novo Nordisk A/S, Bagsvaerd, Denmark) [9] and was reconstituted with the provided diluent immediately prior to administration according to the instructions for use.

Administration to participants in a reclined lateral position was done for simplicity and consistency in a clinical trial setting. A single 3-mg dose of NG was administered into one nostril with the participant lying in a fully reclined lateral position on the side opposite to the nostril in which NG was administered. A single 1-mg dose of GlucaGen was administered 
by intramuscular injection into the deltoid muscle of the non-dominant arm while the participant was lying fully reclined on the side opposite the arm in which the injection was made.

\section{Assessments and End Points}

Participants were instructed to arrive at the clinic at approximately 7 a.m., having fasted for at least $8 \mathrm{~h}$. Participants did not change their basal insulin dose or stop their usual basal insulin infusion rate prior to the procedure to induce hypoglycaemia (PG target of $<3.3$ $\mathrm{mmol} / \mathrm{l}[60 \mathrm{mg} / \mathrm{dl}])$. The last bolus of shortacting insulin was administered approximately $6 \mathrm{~h}$ prior to study drug administration. Participants were in a fasting state prior to hypoglycaemia induction procedure and PG level was $>5.0 \mathrm{mmol} / \mathrm{l}(90 \mathrm{mg} / \mathrm{dl})$ before the start of the procedure.

Hypoglycaemia (plasma glucose, $\mathrm{PG}<3.3$ $\mathrm{mmol} / \mathrm{l}[60 \mathrm{mg} / \mathrm{dl}]$ ) was induced by variable rate intravenous insulin infusion (15-U human regular insulin $[100 \mathrm{U} / \mathrm{ml}]$ in $49-\mathrm{ml}$ saline). Five minutes after stopping insulin, either $3 \mathrm{mg} \mathrm{NG}$ or $1 \mathrm{mg}$ IMG was administered followed by multiple PG measurements up to $90 \mathrm{~min}$. Time to recovery from hypoglycaemia was measured from time of administration and did not include time to prepare each study treatment. After a wash-out period of at least $24 \mathrm{~h}$ and no more than 7 days, participants returned to the clinic for the alternative treatment. The methods of treatment (NG and IMG) were applied in a random, counterbalanced order. In each individual subject, the insulin infusion rates from the first dosing visit were reproduced to induce a similar level of hypoglycaemia at the second dosing visit.

Treatment success was defined as an increase in PG to $\geq 3.9 \mathrm{mmol} / \mathrm{l}(70 \mathrm{mg} / \mathrm{dl})$ or an increase of $\geq 1.1 \mathrm{mmol} / \mathrm{l}(20 \mathrm{mg} / \mathrm{dl})$ from the PG nadir within $30 \mathrm{~min}$ after receiving glucagon, without the participant receiving additional actions to increase blood glucose. The nadir was defined as the minimum glucose value at the time of and within 10 min of glucagon administration.
Laboratory parameters (clinical chemistry, urinalysis, and haematology) and electrocardiogram (ECG) parameters were collected at baseline to assess for safety and suitability for induction of hypoglycaemia.

Safety assessments included spontaneously reported adverse events (AEs) and serious adverse events (SAEs), nasal and non-nasal symptoms solicited through the Nasal/Nonnasal Score Questionnaire [10] (Supplemental Table 1), and vital signs (supine systolic blood pressure, diastolic blood pressure, and heart rate).

\section{Pharmacokinetic and Pharmacodynamic Analyses}

Pharmacokinetic and PD analyses were done for participants who received at least one dose of study drug and had evaluable PK and PD data.

\section{Bioanalytical Methods for Measuring Plasma Glucagon}

Plasma glucagon concentrations were measured using liquid chromatography tandem mass spectrometry at Algorithme Pharma (Laval, Quebec, Canada). Pharmacokinetic parameter estimates for change from baseline of glucagon were performed using Phoenix WinNonlin software, version 6.4 (Certara USA, Princeton, $\mathrm{NJ})$.

\section{Assay Method for Measuring Plasma Glucose Concentrations}

Plasma glucose concentrations used to assess treatment success and PD end points were measured at a central laboratory using the commercially available hexokinase enzymatic method. Assays were performed using the Cobas ${ }^{\circledR} 8000$ modular analyser (Roche Diagnostics, Indianapolis, IN, USA). Plasma glucose concentrations used for safety assessments performed during the procedure to induce hypoglycaemia and the post-treatment recovery period were measured onsite by a laboratory analyser (Super GL glucose analyser; Dr. Müller Gerätebau GmbH, Freital, Germany). 
Table 1 Demographics and baseline characteristics

\begin{tabular}{|c|c|}
\hline Number of participants studied & 70 \\
\hline \multicolumn{2}{|l|}{ Age (years) } \\
\hline Mean (SD) & $41.7(12.7)$ \\
\hline Median & 41.0 \\
\hline Minimum-maximum & $20-64$ \\
\hline \multicolumn{2}{|l|}{ Sex } \\
\hline Male & $43(61.4 \%)$ \\
\hline Female & $27(38.6 \%)$ \\
\hline \multicolumn{2}{|l|}{ Ethnicity } \\
\hline Hispanic or Latino & $0(0 \%)$ \\
\hline Not Hispanic or Latino & $70(100 \%)$ \\
\hline \multicolumn{2}{|l|}{ Race } \\
\hline White & $70(100 \%)$ \\
\hline \multicolumn{2}{|l|}{ Site } \\
\hline 001 & $35(50 \%)$ \\
\hline 002 & $35(50 \%)$ \\
\hline \multicolumn{2}{|l|}{ Weight (kg) } \\
\hline Mean (SD) & $78.79(13.28)$ \\
\hline Median & 78.65 \\
\hline Minimum-maximum & $52.8-114.4$ \\
\hline \multicolumn{2}{|l|}{ Height $(\mathrm{cm})$} \\
\hline Mean (SD) & $175.21(8.43)$ \\
\hline Median & 175.0 \\
\hline Minimum-maximum & $154.0-192.0$ \\
\hline \multicolumn{2}{|l|}{ Body mass index $\left(\mathrm{kg} / \mathrm{m}^{2}\right)$} \\
\hline Mean (SD) & $25.53(2.97)$ \\
\hline Median & 25.40 \\
\hline Minimum-maximum & $19.6-34.5$ \\
\hline \multicolumn{2}{|l|}{ Duration of diabetes (years) } \\
\hline Mean (SD) & $19.8(10.6)$ \\
\hline Median & 20.0 \\
\hline Minimum-maximum & $3-43$ \\
\hline
\end{tabular}

Table 1 continued

Baseline HbAlc (\%)

Mean (SD)

$7.34(0.87)$

Median

7.35

Minimum-maximum

$5.5-9.7$

Baseline $\mathrm{HbAlc}(\mathrm{mmol} / \mathrm{mol})$

Mean (SD)

$50.73(9.52)$

Median

56.84

Minimum-maximum

$36.6-82.5$

Baseline plasma glucose $(\mathrm{mmol} / \mathrm{l})$

$3 \mathrm{mg}$ nasal glucagon group $(N=68)$

Mean (SD)

$3.2(0.3)$

Median

3.2

Minimum-maximum

$2.6-4.2$

$1 \mathrm{mg}$ intramuscular glucagon group $(N=69)$

Mean (SD)

$3.2(0.3)$

Median

3.2

Minimum-maximum

$2.3-4.0$

Baseline alcohol use

Yes

$54(77.1 \%)$

No

$16(22.9 \%)$

Baseline alcohol use (units ${ }^{\dagger}$ per week)

Mean (SD)

Median

2.0

Minimum-maximum

$0-7$

HbAlc haemoglobin A1c, SD standard deviation

${ }^{\dagger}$ Unit $=$ one unit of alcohol equals $12 \mathrm{oz}$ or $360 \mathrm{ml}$ of beer; $5 \mathrm{oz}$ or $150 \mathrm{ml}$ of wine; $1.5 \mathrm{oz}$ or $45 \mathrm{ml}$ of distilled spirits 
Pharmacodynamic parameter estimates for plasma glucose were performed using Phoenix WinNonlin software version 6.4 (Certara USA, Princeton, NJ, USA).

\section{Statistical Analysis}

A total of 66 adult participants with type 1 diabetes completing both treatment visits with evaluable data were required to achieve the primary objective with at least $90 \%$ power. This estimate was based on the following assumptions: treatment success rate of $98 \%$ for both treatments, a non-inferiority margin of $10 \%$, a twosided alpha level of 0.05 , and within-participant correlation of zero between two treatment visits. The study therefore enrolled 70 participants, assuming a 5\% dropout rate. The non-inferiority margin of $10 \%$ was based upon data from a simulated emergency study in which $10 \%$ of the participants (parents of children and adolescents with type 1 diabetes) failed entirely to administer injectable glucagon [2].

The primary efficacy end point, the percentage of participants who achieved treatment success, was assessed for all randomised participants who completed both treatment visits with evaluable data. Non-inferiority of NG was declared if the upper limit of the two-sided 95\% $\mathrm{CI}$ of the difference in percentage of participants achieving treatment success (IMG-NG) was $<10 \%$. The $95 \%$ CI of the treatment difference was calculated using Wald's method with continuity correction [11].

The time to treatment success following glucagon administration was assessed for the participants who completed all dosing visits using Kaplan-Meier analysis. The betweentreatment comparison of time to treatment success was performed using Cox proportional hazard models (exact method) adjusted for baseline glucose and treatment period.

Secondary efficacy end points, including PG, were analysed for all randomised participants who received at least one dose of study drug. A betweentreatment comparison was performed using a linear mixed model with repeated measures.

Safety analysis was conducted for the population that received at least one dose of study drug. Treatment-emergent adverse events (TEAEs) based on the Medical Dictionary for Regulatory Activities (MedDRA), version 18.1, were summarised by treatment, severity, and relationship to the study drug. A TEAE was defined as an $\mathrm{AE}$ that occurred post-dose or was present prior to dosing and became more severe post-dose.

The number and proportion of participants who had an increase in symptom severity category (none, mild, moderate, and severe) from the baseline to $90 \mathrm{~min}$ post-dose period were summarised by treatment group for each symptom included in the Nasal and Non-Nasal Score Questionnaire. All statistical analyses were performed using SAS software, version 9.2 or higher (SAS Institute, Cary, NC, USA).

\section{RESULTS}

\section{Demographics and Disposition}

A total of 70 participants with type 1 diabetes received at least one dose of study drug, and 69 $(98.6 \%)$ completed both study periods. One patient discontinued the study because of an $\mathrm{AE}$ of vomiting that occurred during Period 1 following treatment with NG. The mean age of participants was 41.7 years, and the mean duration of type 1 diabetes was 19.8 years, ranging from 3 to 43 years. The baseline mean HbA1c was $7.3 \%(50.7 \mathrm{mmol} / \mathrm{mol})$. The mean weight was $78.8 \mathrm{~kg}$, with a mean body mass index of $25.4 \mathrm{~kg} / \mathrm{m}^{2}$. All participants were white, with a male predominance (61.4\%). Baseline characteristics are presented in Table 1.

\section{Efficacy}

This study achieved the primary objective by demonstrating non-inferiority of NG to IMG in the percentage of participants achieving treatment success. Of the 66 participants who received both forms of glucagon treatment and had evaluable primary outcome data, 100\% achieved treatment success as defined in the study protocol. Additional analysis showed that $100 \%$ of patients achieved an increase in PG to 
$\geq 3.9 \mathrm{mmol} / \mathrm{l}(70 \mathrm{mg} / \mathrm{dl})$ and an increase of $\geq 1.1 \mathrm{mmol} / \mathrm{l}(20 \mathrm{mg} / \mathrm{dl})$ from the PG nadir within $30 \mathrm{~min}$ of receiving glucagon. The treatment difference was $0.0 \%$ with a two-sided $95 \%$ CI $(-1.52 \%, 1.52 \%)$. Three patients were excluded from the primary efficacy analysis since they had one treatment visit in which the nadir PG concentration was $\geq 3.89 \mathrm{mmol} / \mathrm{l}$ (70 $\mathrm{mg} / \mathrm{dl}$ ), and one patient was excluded because of withdrawal from the study after one treatment visit. The mean nadir glucose was 3.03 (SD: 0.33$) \mathrm{mmol} / \mathrm{l}$ (55.2 [SD: 5.9] $\mathrm{mg} / \mathrm{dl})$ for 3 mg NG and 3.11 (SD: 0.30$) \mathrm{mmol} / \mathrm{l}$ (56.0 [SD: 5.4]) $\mathrm{mg} / \mathrm{dl}$ for $1 \mathrm{mg}$ IMG.

\section{Time to Treatment Success}

In those participants included in the primary efficacy analysis, mean time to treatment success was 11.4 (SD: 3.0 ) $\mathrm{min}$ for $3 \mathrm{mg} \mathrm{NG}$ and 9.9 (SD: 3.0) min for $1 \mathrm{mg}$ IMG. There was a statistically significant difference between treatments in time to achieve treatment success (Fig. 1). At early time points, there was a higher proportion of participants in the 1-mg IMG treatment group achieving treatment success; however, at $15 \mathrm{~min}$ post-dosing $\geq 97 \%$ of patients achieved treatment success in both treatment groups, and by $25 \mathrm{~min}$ post-dose all participants had achieved treatment success.

\section{Pharmacokinetics}

\section{Glucagon}

Glucagon was rapidly absorbed after both nasal and IM administration, and maximum glucagon concentrations were attained by $15 \mathrm{~min}$ post-dose with both routes of administration (Fig. 2). While NG had a higher maximum observed drug concentration $\left(C_{\max }\right)$ compared to IMG (geometric mean of $6130 \mathrm{pg} / \mathrm{ml} \mathrm{vs.} 3750$ $\mathrm{pg} / \mathrm{ml})$, it had a lower area under the concentration versus time curve from time zero to time $t$, where $t$ was the last time point with a measurable concentration AUC( $\left(\right.$ o-tlast $\left._{1}\right)(2740 \mathrm{pg} \bullet \mathrm{h} /$ $\mathrm{ml}$ vs. $3320 \mathrm{pg} \bullet \mathrm{h} / \mathrm{ml}$ ) and appeared to be cleared faster (Supplemental Table 2).

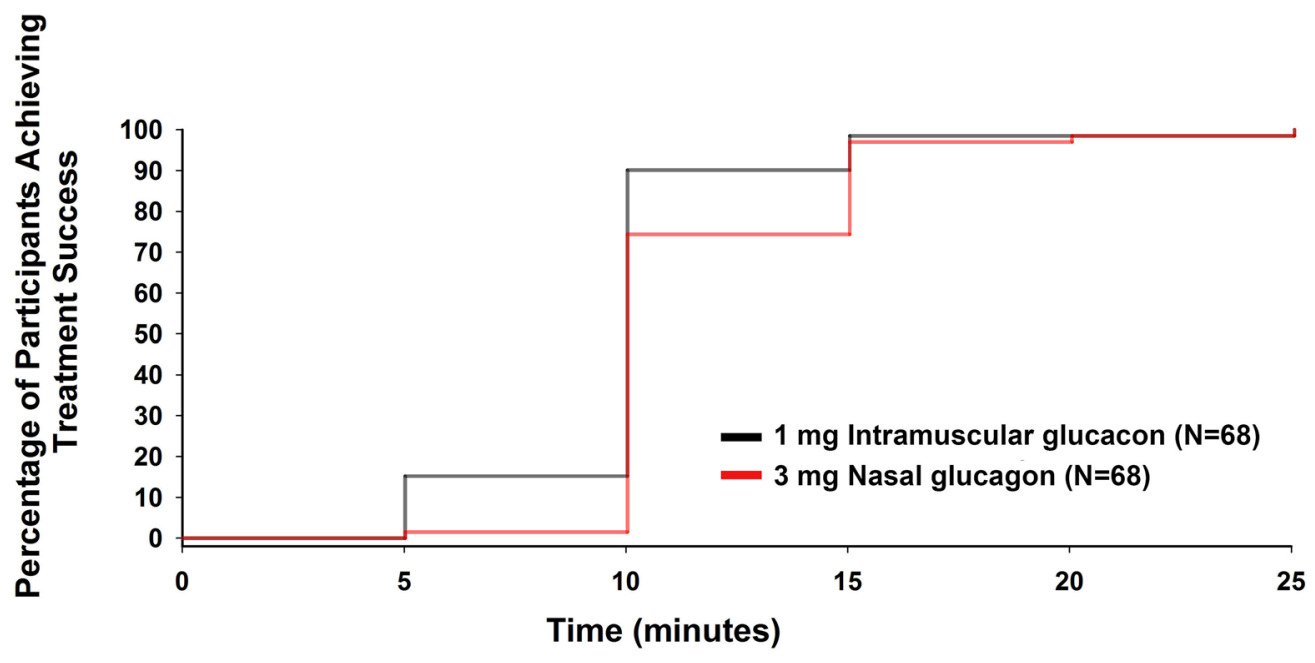

\begin{tabular}{|c|c|c|c|c|c|c|}
\hline \multirow{2}{*}{ Treatment } & \multicolumn{6}{|c|}{ Number of Patients with Treatment Success (\%) } \\
\hline & $0 \mathrm{~min}$ & $5 \mathrm{~min}$ & $10 \mathrm{~min}$ & $15 \mathrm{~min}$ & $20 \min$ & $25 \mathrm{~min}$ \\
\hline $1 \mathrm{mg}$ IM glucagon, $\mathrm{N}=66$ & $0(0)$ & $10(15.2)$ & $60(90.1)$ & $65(98.5)$ & $65(98.5)$ & $66(100)$ \\
\hline $3 \mathrm{mg}$ Nasal glucagon, $\mathrm{N}=66$ & $0(0)$ & $1(1.5)$ & $49(74.4)$ & $64(97.0)$ & $65(98.5)$ & $66(100)$ \\
\hline
\end{tabular}

Fig. 1 Kaplan-Meier curve for the time to treatment success (an increase in PG to $\geq 3.9 \mathrm{mmol} / \mathrm{l}[70 \mathrm{mg} / \mathrm{dl}]$ or a PG increase of $\geq 1.1 \mathrm{mmol} / 1[20 \mathrm{mg} / \mathrm{dl}]$ from nadir) within $30 \mathrm{~min}$ following $3 \mathrm{mg}$ nasal glucagon and $1 \mathrm{mg}$
GlucaGen ${ }^{\circledR}$ treatment in participants who completed all dosing visits. Red line $=3 \mathrm{mg}$ nasal glucagon $(N=68)$; black line $=1 \mathrm{mg}$ intramuscular glucagon $(N=69)$. $I M$ intra-muscular, $P G$ plasma glucose 

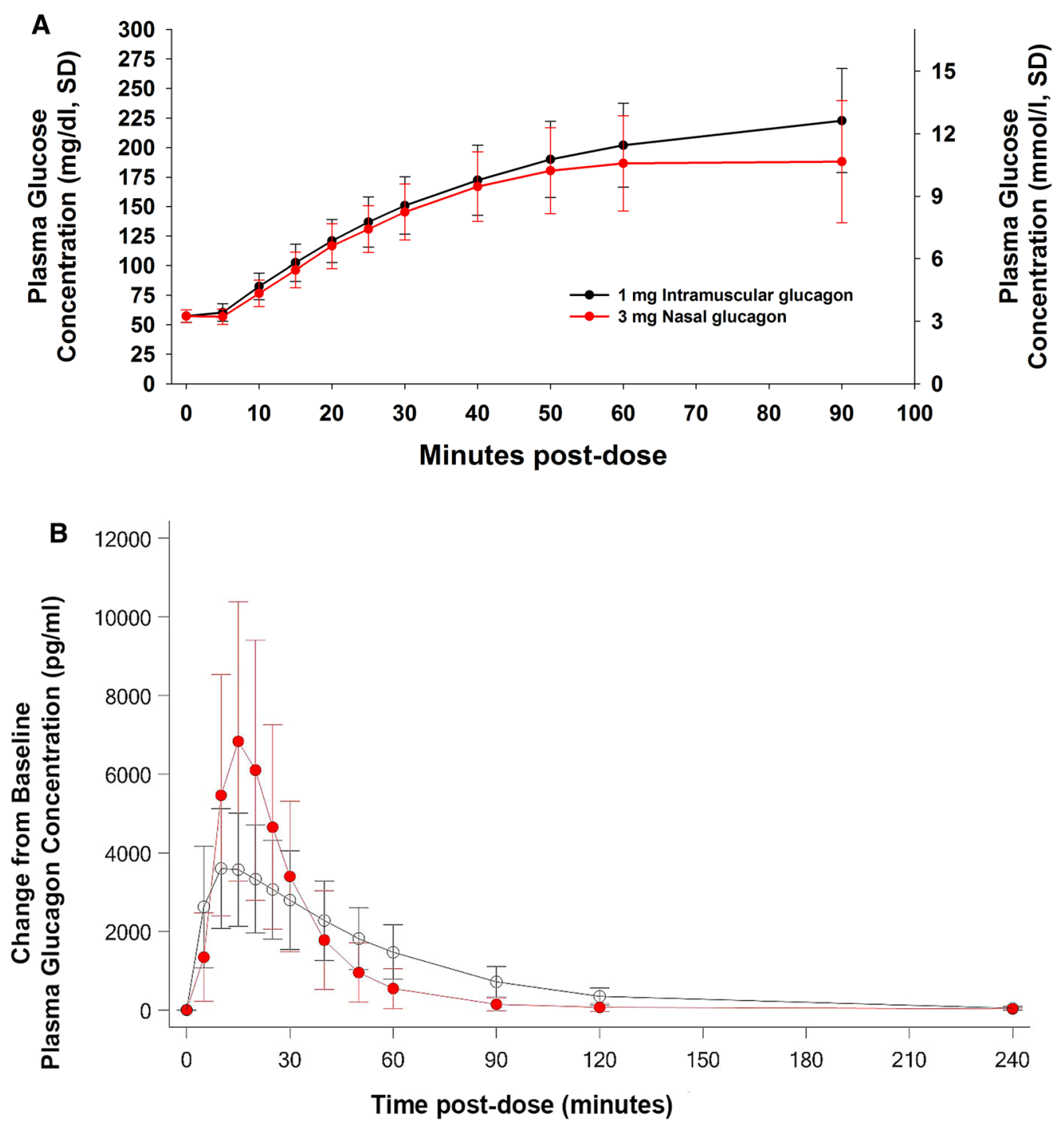

$3 \mathrm{mg}$ Nasal glucagon $1 \mathrm{mg}$ Intramuscular glucagon

Fig. 2 a Arithmetic mean ( \pm SD) profile of plasma glucose concentration after a single dose of $3 \mathrm{mg} \mathrm{NG}$ or 1 mg IMG. Red circles and line $=3 \mathrm{mg}$ nasal glucagon $(N=$ 68; baseline mean PG $=3.2 \mathrm{mmol} / \mathrm{l} ; \mathrm{SD}=0.3$ ); white circle and black line $=1 \mathrm{mg}$ intramuscular glucagon $(N=$ 69; baseline mean PG $=3.2 \mathrm{mmol} / \mathrm{l} ; \mathrm{SD}=0.3)$. $\mathbf{b}$ Change

\section{Pharmacodynamics}

Similar PG responses were observed with both 3 $\mathrm{mg}$ NG and $1 \mathrm{mg}$ IMG for the first 40 min postdose. While a continuous increase of PG up to $90 \mathrm{~min}$ was observed for $1 \mathrm{mg}$ IMG, a plateau from baseline plasma glucagon concentration $( \pm S D)$ following single doses of $3 \mathrm{mg}$ nasal glucagon or $1 \mathrm{mg}$ GlucaGen. Red circles and line $=3 \mathrm{mg}$ nasal glucagon $(N=68)$; white circle and black line $=1 \mathrm{mg}$ intramuscular glucagon $(N=69)$. min minutes, $S D$ standard deviation

was reached for $3 \mathrm{mg}$ NG by $60 \mathrm{~min}$ (Fig. 2a). The maximal blood glucose $\left(\mathrm{BG}_{\max }\right)$ change from baseline was significantly different $(p<0.0001)$ between treatment groups: geometric least squares (LS) mean was $7.3 \mathrm{mmol} / \mathrm{l}$ (131.2 mg/dl) for $3 \mathrm{mg} \mathrm{NG}$ and $8.9 \mathrm{mmol} / \mathrm{l}(160.3$ $\mathrm{mg} / \mathrm{dl})$ for $1 \mathrm{mg}$ IMG. The AUC($(0-1.5)$ change from 
Table 2 Treatment-emergent adverse events by order of frequency

\begin{tabular}{|c|c|c|c|}
\hline \multirow[t]{2}{*}{ MedDRA $^{a}$ preferred term } & \multicolumn{3}{|c|}{$\begin{array}{l}\text { Number of TEAEs } \\
\text { Related to study treatment } \\
\text { (Number of participants with TEAEs) }\end{array}$} \\
\hline & $\begin{array}{l}\mathrm{mg} \\
\text { Nasal glucagon } \\
N=70 \\
n(\%)\end{array}$ & $\begin{array}{l}1 \mathrm{mg} \\
\text { GlucaGen® } \\
N=69 \\
n(\%)\end{array}$ & $\begin{array}{l}\text { Total } \\
N=70 \\
n(\%)\end{array}$ \\
\hline Nausea & $22(31.4)$ & $29(42.0)$ & $38(54.3)$ \\
\hline Vomiting & $10(14.3)$ & $12(17.4)$ & $19(27.1)$ \\
\hline Headache & $11(15.8)$ & $7(10.0)$ & $18(25.8)$ \\
\hline Abdominal discomfort & $1(1.4)$ & $0(0)$ & $1(1.4)$ \\
\hline Abdominal pain upper & $0(0)$ & $1(1.4)$ & $1(1.4)$ \\
\hline Body temperature increase & $0(0)$ & $1(1.4)$ & $1(1.4)$ \\
\hline Diarrhoea & $0(0)$ & $1(1.4)$ & $1(1.4)$ \\
\hline Eye pain & $1(1.4)$ & $0(0)$ & $1(1.4)$ \\
\hline Hyperhidrosis & $1(1.4)$ & $0(0)$ & $1(1.4)$ \\
\hline Ocular discomfort & $1(1.4)$ & $0(0)$ & $1(1.4)$ \\
\hline
\end{tabular}

MedDRA Medical Dictionary for Regulatory Activities, $N$ total number of participants, $n$ number of participants in a specific category, TEAE treatment-emergent adverse event

${ }^{a}$ MedDRA version 18.1

baseline was also statistically different between treatments: geometric LS mean values were $132.83 \mathrm{mg} \bullet \mathrm{h} / \mathrm{dl}$ for $3 \mathrm{mg} \mathrm{NG}$ and $154.90 \mathrm{mg} \bullet \mathrm{h} / \mathrm{dl}$ for $1 \mathrm{mg}$ IMG (Supplemental Table 3).

\section{Safety}

The overall number of participants reporting a TEAE and the number of TEAEs were generally similar between treatment groups (Supplemental Table 4). The majority of TEAEs in each treatment group were mild in severity and none were severe. Of the 50 TEAEs reported in the NG treatment group, 48 were considered by the investigator to be related to study treatment. Of the 51 TEAEs reported in the IMG treatment group, all were related to study treatment. One participant discontinued the study because of an $\mathrm{AE}$ of vomiting that occurred during Period 1 following treatment with NG. No participants discontinued because of an $\mathrm{AE}$ in the IMG treatment group. No deaths or other SAEs occurred during this study.

The most commonly reported TEAEs were nausea and vomiting (Table 2). The frequency of nausea and vomiting, and the number of participants reporting these events, were generally comparable between the two treatment groups.

A summary of the frequency of participants with an increase from baseline severity in nasal and non-nasal symptoms post-dose is provided in Table 3. Symptoms experienced by $\geq 10 \%$ of participants who reported worsening of symptom severity after NG administration (up to 90 min) included watery eyes, nasal itching, nasal congestion, runny nose, sneezing, redness of eyes, itchy eyes, and itching of throat. Most were rated by the patient as mild or moderate. Watery eyes, nasal congestion, nasal itching, and itchy eyes were the symptoms NG-treated patients most frequently reported $(>2 \%)$ as shifting from non-severe at baseline to severe at 
Table 3 Number of participants with increased severity of solicited nasal and non-nasal symptoms over the 90-min postdose assessment period

\begin{tabular}{|c|c|c|c|c|}
\hline Symptom & $\begin{array}{l}3 \mathrm{mg} \text { Nasal glucagon } \\
N=70 n(\%) \\
\text { Severity increased at any } \\
\text { to } 90 \mathrm{~min}\end{array}$ & $\begin{array}{l}1 \mathrm{mg} \text { GlucaGen }{ }^{\circledR} \\
N=69 n(\%) \\
\text { ost-dose time point up }\end{array}$ & $\begin{array}{l}3 \mathrm{mg} \text { Nasal glucagon } \\
N=70 n(\%) \\
\text { Severity increased at } 90\end{array}$ & $\begin{array}{l}1 \mathrm{mg} \text { GlucaGen }{ }^{\circledR} \\
N=69 n(\%) \\
\text { nin post-dose }\end{array}$ \\
\hline Runny nose & $26(37.1)$ & 0 & $9(12.9)$ & 0 \\
\hline $\begin{array}{l}\text { Nasal } \\
\text { congestion }\end{array}$ & $27(38.6)$ & $3(4.3)$ & $14(20.0)$ & $2(2.9)$ \\
\hline Nasal itching & $34(48.6)$ & 0 & $19(27.1)$ & 0 \\
\hline Sneezing & $17(24.3)$ & 0 & $4(5.7)$ & 0 \\
\hline Watery eyes & $44(62.9)$ & 0 & $12(17.1)$ & 0 \\
\hline Itchy eyes & $14(20.0)$ & $1(1.4)$ & $6(8.6)$ & 0 \\
\hline $\begin{array}{l}\text { Redness of } \\
\text { eyes }\end{array}$ & $15(21.4)$ & 0 & $8(11.4)$ & 0 \\
\hline Itching of ears & $2(2.9)$ & 0 & 0 & 0 \\
\hline $\begin{array}{c}\text { Itching of } \\
\text { throat }\end{array}$ & $9(12.9)$ & 0 & $3(4.3)$ & 0 \\
\hline
\end{tabular}

$N$ number of participants, $n$ number of participants in a specific category

Increase from baseline severity in nasal and non-nasal symptoms is absolute change from baseline in total score of the Nasal and Non-nasal Score Questionnaire. Baseline severity is defined as the severity score prior to glucagon administration at each treatment visit

any post-baseline time point, but no symptoms were reported as serious events. In addition, no symptoms shifted from non-severe to severe at 90 min post-dose.

During the study, including the follow-up visit, there were no clinically significant alterations in clinical laboratory values, vital sign values, or ECG parameters.

\section{DISCUSSION}

The present study provides data that in a randomised open-label, two-period, crossover study $3 \mathrm{mg}$ NG is non-inferior to $1 \mathrm{mg}$ IMG in the proportion of type 1 diabetes participants achieving treatment success following controlled insulin-induced hypoglycaemia. In fact, all participants in each treatment group achieved treatment success, similar to the results seen in the study by Rickels et al. [8]. For patients with a nadir $<2.8 \mathrm{mmol} / \mathrm{l}(<50 \mathrm{mg} / \mathrm{dl})$ in both periods, $100 \%(3 / 3)$ achieved treatment success. Time to treatment success was achieved sooner in participants who received IMG. However, it is worth noting that the calculation of time to treatment success did not include the 2 min needed to prepare IMG for administration. In addition, because this study took place in an outpatient clinical setting, these results may differ from a real-world emergency requiring the help of a non-healthcare provider.

Administration of injectable glucagon can be complicated by errors and failures to administer the drug by non-medical caregivers in a demanding situation $[2,3]$. The process and preparation for the injection may delay or even preclude treatment altogether, especially when caregivers are required to cope with such a stressful emergency. In a simulation study, Yale 
et al. (2017) reported that only two caregivers $(13 \%)$ were able to successfully administer a full dose of IMG. Because of its ease of use, NG is expected to have a higher success rate. In the simulation study, $93 \%$ of caregivers and acquaintances successfully administered a full dose of NG.

In the present study, during recovery from the insulin induced hypoglycaemia, NG and IMG glucose response curves were similar. These glucose responses were sufficient for the patients to recover and actively take oral carbohydrate or perform other resuscitative actions. Although the maximum glucose achieved was higher for IMG (Fig. 2a), all NG subjects achieved normoglycaemia. A lower maximum glucose may be advantageous if it translates to less frequent secondary hyperglycaemia that may require additional treatment with insulin. Evidence from a clinical study suggests potential harm through an increase in cardiovascular risk factors to type 1 diabetes patients that experience hyperglycaemia after recovery from hypoglycaemia [12].

Nasal glucagon was rapidly absorbed with faster clearance and achieved a higher $C_{\text {max }}$, but lower AUC, compared to IMG. However, there was no apparent effect of the higher $C_{\max }$ on the safety profile. With the exception of nasal and non-nasal symptoms related to the nasal route of administration, TEAEs reported for NG were consistent with known glucagon class effect and were similar to IMG group.

Overall, NG was well tolerated, with no severe TEAEs, or SAEs, reported. The number of participants reporting a TEAE and the number of TEAEs reported were similar between the two treatment groups. The most frequent TEAEs in both treatment groups were nausea and vomiting, consistent with the two most common adverse reactions associated with currently marketed IMG products, the GlucaGen HypoKit (Novo Nordisk) and the Glucagon Emergency Kit (Eli Lilly and Company, Indianapolis, IN, USA). The majority of TEAEs were mild and none were severe for either treatment. Unsurprisingly, these observations are consistent with the safety profile for glucagon that is well established and rooted in $>50$ years of clinical use.
As expected, more nasal and non-nasal symptoms occurred in NG-treated participants [8.13]. Symptoms experienced by $\geq 10 \%$ of participants who reported worsening of symptom severity after NG administration were watery eyes, nasal itching, nasal congestion, runny nose, sneezing, redness of eyes, itchy eyes, and itching of throat.

Limitations of the present study include the fact that recovery from insulin-induced severe hypoglycaemia was not tested because of ethical concerns of reducing glucose levels to the point of reduced consciousness or induction of a seizure [8]. However, in real-world studies of the effectiveness and ease of use of NG in the treatment of moderate and severe hypoglycaemia events, similar results were reported $[13,14]$.

Additional limitations include the fact that study treatments were not blinded for the assessment of AEs and that the present study did not capture the ease of use of NG.

\section{CONCLUSIONS}

A single 1-mg dose of IMG is used as a rescue treatment for severe hypoglycaemia. Under conditions of insulin-induced hypoglycaemia, NG is well tolerated and non-inferior to 1-mg IMG by treatment success.

\section{ACKNOWLEDGEMENTS}

The authors wish to thank the participants of this study.

Funding. Eli Lilly and Company provided funding for this study and the journal's Rapid Service Fee.

Medical Writing Assistance. The authors thank Kent Steinriede, MS, CMPP, of Syneos Health for providing writing assistance funded by Eli Lilly and Company.

Authorship. All named authors meet the International Committee of Medical Journal Editors (ICMJE) criteria for authorship for this 
article, take responsibility for the integrity of the work as a whole, and have given their approval for this version to be published.

Authorship Contributions. J.G.S. contributed to the conception and design of the study, analysis and interpretation of the data, and critical revision of the manuscript for important intellectual content. U.H. contributed to the design of the study, acquisition of the data, and critical revision of the manuscript for important intellectual content. S.Z. contributed to the conception and design of the study, acquisition, analysis and interpretation of the data, and drafting and critical revision of the manuscript for important intellectual content. T.S. contributed to the design of the study, analysis and interpretation of the data, and drafting and critical revision of the manuscript for important intellectual content. B.B. contributed to the design of the study and drafting of the manuscript for important intellectual content. J.S. contributed to interpretation of data for the work and critical revision of the manuscript for important intellectual content. E.Z. contributed to the design of the study, acquisition and interpretation of the data, and critical revision of the manuscript for important intellectual content. B.M.F. contributed to interpretation of data for the work and critical revision of the manuscript for important intellectual content. L.P.-M. contributed to the acquisition and interpretation of the data and critical revision of the manuscript for important intellectual content. J.G.S. is the guarantor of this work and, as such, had full access to all the data in the study and takes responsibility for the integrity of the data and the accuracy of the data analysis.

Prior Presentation. Parts of this work were presented as an oral presentation at the 54th European Association for the Study of Diabetes Annual Meeting in Berlin, Germany, October 1-5, 2018; Diabetes Canada/Canadian Society of Endocrinology and Metabolism 21st Professional Conference and Annual Meetings, Halifax, NS, October 10-13, 2018; Chinese Diabetes Society. Suzhou, China, November 28-December 1, 2018; Advanced Technologies \&
Treatments for Diabetes, 12th International Conference, Berlin, Germany; February 20-23, 2019; Société Francophone du Diabète, 45th Annual Congress, Marseilles, France, March 26-29, 2019; Japan Diabetes Society, 63rd Annual Meeting, Otsu, Japan, May 21-23, 2019; Swedish Society for Diabetology, 2019 Annual Conference, Stockholm, Sweden, March 13-15, 2019; German Diabetes Association, 54th Annual Conference, Berlin, Germany, May 29-June 1.

Disclosures. Jeffrey G. Suico, Shuyu Zhang and Brandon Bergman are employees of Eli Lilly and Company and own stock in Eli Lilly. Ulrike Hövelmann has nothing to disclose. Tong Shen was an employee of Eli Lilly at the time the study was performed, but is now an employee of Alexion Pharmaceuticals. Jennifer Sherr reports consulting fees from Medtronic Diabetes, Lexicon, Eli Lilly, and Sanofi and serving on scientific advisory boards for Eli Lilly, Insulet Corporation, Bigfoot Biomedical, and Cecilia Health. Eric Zijlstra reports grants and non-financial support from Eli Lilly and personal fees and non-financial support from Novo Nordisk and Roche Diabetes Care. Brian M. Frier reports personal fees from Eli Lilly, Novo Nordisk, Merck Sharp \& Dohme, Abbott, Roche, Locemia Solutions, Zucara Therapeutics, and Sanofi. Leona Plum-Mörschel reports speaker honoraria and travel reimbursement from Eli Lilly.

Compliance with Ethics Guidelines. The study was conducted in accordance with the ethical principles of the Declaration of Helsinki and International Conference on Harmonisation's Guideline for Good Clinical Practice. The protocol was approved by the ethical committee of Ärztekammer Nordrhein Düsseldorf, Germany and by the Ethik-Kommission der Landesärztekammer Mainz, Germany. All participants provided written informed consent.

Data Availability. The datasets during and/ or analysed during the current study are available from the corresponding author on reasonable request. 
Open Access. This article is licensed under a Creative Commons Attribution-NonCommercial 4.0 International License, which permits any non-commercial use, sharing, adaptation, distribution and reproduction in any medium or format, as long as you give appropriate credit to the original author(s) and the source, provide a link to the Creative Commons licence, and indicate if changes were made. The images or other third party material in this article are included in the article's Creative Commons licence, unless indicated otherwise in a credit line to the material. If material is not included in the article's Creative Commons licence and your intended use is not permitted by statutory regulation or exceeds the permitted use, you will need to obtain permission directly from the copyright holder. To view a copy of this licence, visit http://creativecommons.org/licenses/by$\mathrm{nc} / 4.0 /$.

\section{REFERENCES}

1. International Hypoglycaemia Study Group. Glucose concentrations of less than $3.0 \mathrm{mmol} / \mathrm{l}(54 \mathrm{mg} / \mathrm{dL})$ should be reported in clinical trials: a joint position statement of the American Diabetes Association and the European Association for the Study of Diabetes.Diabetes Care. 2017;40(1):155-7. https:// doi.org/10.2337/dc16-2215.

2. Harris G, Diment A, Sulway M, Wilkinson M. Glucagon administration-underevaluated and undertaught. Practical Diabetes Int. 2001;18(1):22-5.

3. Yale JF, Dulude H, Egeth $M$, et al. Faster use and fewer failures with needle-free nasal glucagon versus injectable glucagon in severe hypoglycemia rescue: A simulation study. Diabetes Technol Ther. 2017;19(7):423-32.

4. Pontiroli AE. Intranasal glucagon: a promising approach for treatment of severe hypoglycemia. J Diabetes Sci Technol. 2015;9(1):38-43.

5. Kedia N. Treatment of severe diabetic hypoglycemia with glucagon: an underutilized therapeutic approach. Diabetes Metab Syndr Obes. 2011;4: 337-46.

6. Yardley D, Lyddall A, Richardson J, et al. Glucagon injection for type 1 diabetes in children. Nurs Child Young People. 2011;23(9):12-8.

7. Glucagon (Glucagon for Injection). Eli Lilly and Company, Indianapolis, IN, USA. [Prescribing information], 2018. Available from: URL:https:// uspl.lilly.com/glucagon/glucagon.html\#pi. Accessed 01 May 2019.

8. Rickels MR, Ruedy KJ, Foster NC, et al. Intranasal glucagon for treatment of insulin-induced hypoglycemia in adults with type 1 diabetes: A randomized crossover noninferiority study. Diabetes Care. 2016;39(2):264-70.

9. GlucaGen (glucagon for injection $1 \mathrm{mg} / \mathrm{mL}$ ). Novo Nordisk A/S, Denmark. [Prescribing Information], 2018. Available from: https://www.novo-pi.com/ glucagenhypokit.pdf. Accessed 24 Apr 2019.

10. Simons FE, Prenner BM, Finn A Jr Desloratadine Study Group. Efficacy and safety of desloratadine in the treatment of perennial allergic rhinitis. J Allergy Clin Immunol. 2003; 111(3):617-22.

11. Newcombe RG. Improved confidence intervals for the difference between binomial proportions based on paired data. Stat Med. 1998;17(22):2635-50.

12. Ceriello A, Novials A, Ortega E, et al. Hyperglycemia following recovery from hypoglycemia worsens endothelial damage and thrombosis activation in type 1 diabetes and in healthy controls. Nutr Metab Cardiovasc Dis. 2014;24(2):116-23.

13 Seaquist ER, Dulude H, Zhang XM, et al. Prospective study evaluating the use of nasal glucagon for the treatment of moderate to severe hypoglycaemia in adults with type 1 diabetes in a real-world setting. Diabetes Obes Metab. 2018;20(5):1316-20.

14. Deeb LC, Dulude H, Guzman CB, et al. A phase 3 multicenter, open-label, prospective study designed to evaluate the effectiveness and ease of use of nasal glucagon in the treatment of moderate and severe hypoglycemia in children and adolescents with type 1 diabetes in the home or school setting. Pediatr Diabetes. 2018;19(5):1007-13. https://doi. org/10.1111/pedi.12668. 